\title{
ESTADO DE ALARMA O DE EXCEPCIÓN
}

\author{
Francisco Javier Álvarez García ${ }^{1}$
}

1. No cabe duda de que la pandemia que estamos soportando en España (y en el mundo) exige una cierta disciplina ciudadana para poder sobrevivir a ella; y tampoco existe incertidumbre alguna, si se sigue lo que preconizan los expertos, que ello debe implicar confinamiento de los ciudadanos.

Pues bien, el artículo 116 de la Constitución española, por lo que ahora nos interesa, ha venido a regular el elenco de las crisis más importantes que se pueden plantear en la vida del Estado ("imposibilidad en que se encuentran las autoridades competentes para mantener mediante 'los poderes ordinarios' la normalidad ante la emergencia de determinadas circunstancias extraordinarias", ATC 7/2012, de 13 de enero). Se trata de situaciones que han sido de declaración frecuente a lo largo de

Recibido: marzo 2020. Aceptado: marzo 2020

1 Catedrático de Derecho Penal. ORCID ID: https://orcid.org/0000-0002$\underline{9608-5920}$

Departamento de Derecho Penal, Procesal e Historia del Derecho. Facultad de Ciencias Sociales y Jurídicas. Universidad Carlos III de Madrid. Calle Madrid, 126, 28903 Getafe, Madrid. E-mail: falvarez@der-pu.uc3m.es 
nuestra más que turbulenta vida política desde el 1808 hasta el final de nuestra última Guerra Civil, y aún en distintas ocasiones durante la más reciente Dictadura ante el menor atisbo de agitación política ${ }^{2}$, obviamente en unas circunstancias políticas que nada tienen que ver con las actuales presididas por una Constitución democrática.

Así, el citado artículo 116 CE, preceptúa:

“1. Una ley orgánica regulará los estados de alarma, de excepción y de sitio, y las competencias y limitaciones correspondientes.

2. El estado de alarma será declarado por el Gobierno mediante decreto acordado en Consejo de Ministros por un plazo máximo de quince días, dando cuenta al Congreso de los Diputados, reunido inmediatamente al efecto y sin cuya autorización no podrá ser prorrogado dicho plazo. El decreto determinará el ámbito territorial a que se extienden los efectos de la declaración.

3. El estado de excepción será declarado por el Gobierno mediante decreto acordado en Consejo de Ministros, previa autorización del Congreso de los Diputados. La autorización y proclamación del estado de excepción deberá determinar expresamente los efectos del mismo, el ámbito territorial a que se extiende y su duración, que no podrá exceder de treinta días, prorrogables por otro plazo igual, con los mismos requisitos".

Por su parte el artículo 55.1 del mismo texto reza lo que sigue:

2 Por ejemplo, y entre otros: Decreto-Ley 13/1962, de 4 de mayo, por el que se declara el Estado de Excepción en algunas zonas industriales; Decretoley $1 / 1969$, de 24 de enero, por el que se declara el estado de excepción en todo el territorio nacional, y Decreto-ley 4/1975, de 25 de abril, por el que se declara el estado de excepción en las provincias de Guipúzcoa y Vizcaya. 
"Los derechos reconocidos en los artículos 17, 18, apartados 2 y 3, artículos 19, 20, apartados 1, a) yd), y 5, artículos 21, 28, apartado 2, y artículo 37, apartado 2, podrán ser suspendidos cuando se acuerde la declaración del estado de excepción o de sitio en los términos previstos en la Constitución. Se exceptúa de lo establecido anteriormente el apartado 3 del artículo 17 para el supuesto de declaración de estado de excepción".

Los derechos a los que se refiere el precepto acabado de reproducir, son los siguientes: a la libertad y seguridad (art. 17, $\mathrm{CE}$ ); a la inviolabilidad del domicilio y secreto de las comunicaciones (art. 18.2 y 3, CE); a fijar la residencia y a circular libremente por todo el territorio nacional, así como a entrar y salir libremente del territorio nacional (art. 19, CE); a la libre expresión e información y al no secuestro de las publicaciones sin autorización judicial [artículo 20.1 a) y d) y 5, CE]; de reunión (art. 21, CE); de huelga (art. 28.2, CE), y al conflicto colectivo (art. 37.2, CE).

Como no podía ser de otra manera, y aplicando el precepto constitucional, se dictó por las Cortes la Ley Orgánica 4/1981, de 1 de junio, de los estados de alarma, excepción y sitio, en la que se dio desarrollo al citado artículo $116 \mathrm{CE}$, y que en su artículo Primero preceptuaba:

"Uno. Procederá la declaración de los estados de alarma, excepción o sitio cuando circunstancias extraordinarias hiciesen imposible el mantenimiento de la normalidad mediante los poderes ordinarios de las Autoridades competentes.

Dos. Las medidas a adoptar en los estados de alarma, excepción y sitio, así como la duración de los mismos, serán en cualquier caso las estrictamente indispensables para asegurar el restablecimiento de la normalidad. Su aplicación se realizará de forma proporcionada a las circunstancias ". 
2. El artículo Cuarto de la anterior LO 4/1981 establece que:

"El Gobierno, en uso de las facultades que le otorga el artículo ciento dieciséis, dos, de la Constitución podrá declarar el estado de alarma, en todo o parte del territorio nacional, cuando se produzca alguna de las siguientes alteraciones graves de la normalidad.

a) Catástrofes, calamidades o desgracias públicas, tales como terremotos, inundaciones, incendios urbanos y forestales o accidentes de gran magnitud.

b) Crisis sanitarias, tales como epidemias y situaciones de contaminación graves.

c) Paralización de servicios públicos esenciales para la comunidad, cuando no se garantice lo dispuesto en los artículos veintiocho, dos, y treinta y siete, dos, de la Constitución, concurra alguna de las demás circunstancia o situaciones contenidas en este artículo.

d) Situaciones de desabastecimiento de productos de primera necesidad".

No cabe duda, pues, que el Gobierno podía declarar el "estado de alarma", pues se dan tanto las circunstancias objetivas (epidemia), como la atribución de competencia para hacerlo.

3. La cuestión a discutir, ahora, consiste, exclusivamente, en valorar si el contenido material del Real Decreto 463/2020, de 14 de marzo, por el que se declara el estado de alarma para la gestión de la situación de crisis sanitaria ocasionada por el COVID-19, se corresponde o excede las previsiones constitucionales para ese "estado".

Al contenido del estado de alarma se refiere la STC 83/2016, de 28 de abril, cuando afirma: "Los efectos de la declaración del estado de alarma se proyectan en la modificación del ejercicio de competencias por parte de la Administración y las autoridades públicas y en el establecimiento de determinadas 
limitaciones o restricciones", y más adelante: "A diferencia de los estados de excepción y de sitio, la declaración del estado de alarma no permite la suspensión de ningún derecho fundamental (art. 55.1 CE contrario sensu), aunque sí la adopción de medidas que pueden suponer limitaciones o restricciones a su ejercicio. En este sentido, se prevé, entre otras, como medidas que pueden ser adoptadas, la limitación de la circulación o permanencia de personas o vehículos en lugares determinados o condicionarlas al cumplimiento de ciertos requisitos". En este mismo sentido, con claridad, ALEGRE ÁVILA y SÁNCHEZ LAMELA $^{3}$

A la incapacidad del estado de alarma para suspender derechos fundamentales (ex artículo 55.1 CE), no se opone el que el art. 3 de la Ley Orgánica 3/1986, de 14 de abril, de Medidas Especiales en Materia de Salud Pública, asevere: "Con el fin de controlar las enfermedades transmisibles, la autoridad sanitaria, además de realizar las acciones preventivas generales, podrá adoptar las medidas oportunas para el control de los enfermos, de las personas que estén o hayan estado en contacto con los mismos y del medio ambiente inmediato, así como las que se consideren necesarias en caso de riesgo de carácter transmisible" . Ello por un motivo evidente: la LO no puede derogar un precepto constitucional, lo que obliga a que esa inconcreta cláusula de que la autoridad sanitaria podrá adoptar "las [medidas] que se consideren necesarias", hay que entenderla no como equivalente a una habilitación a las autoridades sanitarias para proceder a una suspensión de derechos con carácter general, sino a una autorización para proceder a meras restricciones o limitaciones de los mismos con carácter particular (no se debe

3 ALEGRE ÁVILA, JM y SÁNCHEZ LAMELA, A (2020), "Nota en relación a la crisis sanitaria generada por la actual emergencia vírica", recuperado de http://www.aepda.es/ AEPDAEntrada-2741-Nota-en-relacion-a-lacrisis-sanitaria-generada-por-la-actual-emergencia-virica.aspx.

4 Otros preceptos en materia sanitaria que vienen a reforzar esta disposición, son los siguientes: artículos 26 de la Ley 14/1986, de 25 de abril, General de Sanidad, y 54 de la Ley 33/2011, de 4 de octubre, General de Salud Pública. 
caer en la tentación de interpretar el precepto constitucional de acuerdo a las normas ordinarias, incluso hasta vaciar a aquél de contenido; por el contrario, se trata de incorporar la norma ordinaria en el sistema jurídico constitucional, fuera del cual carece de existencia).

4. La cuestión es ahora, pues, determinar si la aplicación del estado de alarma por el RD ha supuesto una mera limitación al ejercicio de determinados derechos fundamentales, o, por el contrario, una verdadera suspensión de los mismos.

A este propósito no es inoportuno traer a colación el Real Decreto $1673 / 2010$, de 4 de diciembre, por el que se declara el estado de alarma para la normalización del servicio público esencial del transporte aéreo, declaraba en su Preámbulo:

"El artículo 19 de la Constitución española reconoce a todos los españoles el derecho a la libre circulación por todo el territorio nacional. Dicho derecho está igualmente reconocido a todas las personas en los Tratados y Convenios Internacionales de los que España es parte.

Las circunstancias extraordinarias que concurren por el cierre del espacio aéreo español como consecuencia de la situación desencadenada por el abandono de sus obligaciones por parte de los controladores civiles de tránsito aéreo, impiden el ejercicio del derecho fundamental mencionado y determinan la paralización de un servicio público esencial para la sociedad como lo es el servicio de transporte aéreo".

Pues bien: resulta llamativo que en este Preámbulo se justificase la declaración del estado de alarma, por huelga de los controladores aéreos, en que la situación desencadenada por estos: "impiden el ejercicio del derecho fundamental mencionado [artículo 19 de la CE, libre circulación por el territorio nacional]", y que, sin embargo, el confinamiento de los ciudadanos en sus casas con la prohibición prácticamente absoluta 
de desplazamiento, se entienda sólo como una limitación de la libertad de movimiento de las personas. Digo que resulta llamativo, porque en el caso de los controladores el cierre del espacio aéreo español únicamente impedía la libre circulación en dicho medio, no la "libre circulación" en general, la que se podía ejercer mediante otro tipo de transporte (tren, vehículo privado, andando); es decir: no se impedía la libertad de circulación, sino la realización de tal movimiento a través de medios aéreos. Una precisión más: el argumento de que la imposibilidad de viajar en avión impedía realmente el ejercicio del derecho del artículo $19 \mathrm{CE}$ cuando los citados viajes consistieran en larguísimos trayectos (por ejemplo, al "otro lado" del Atlántico), lo que de facto supondría -según esta interpretación- un impedimento al libre ejercicio del derecho, tampoco es acogible, ya que el artículo $19 \mathrm{CE}$ lo que garantiza es la libre circulación en el territorio nacional, no en espacios sometidos a otra soberanía en la que sea aplicable otro Ordenamiento. Así las cosas, no creo que pueda alegarse, con seriedad y rigor, impedimento de la libre circulación, cuando se goza de otros medios e infraestructuras costosísimas en términos presupuestarios, que permiten que los desplazamientos más largos en la Península puedan hacerse en pocas horas, incluso los por realizar a las Baleares o a las plazas de soberanía, y sólo el acudir a las Islas Canarias puede llevar un mayor tiempo, que en cualquier caso no es impeditivo.

5. En este punto hay que centrar la cuestión en la diferencia entre "limitación" o "restricción" del derecho fundamental, y suspensión del mismo, aun partiendo del dato de que, como apunta el TEDH, entre "privación" y "restricción de libertad" no hay más que una diferencia de grado o de intensidad, no de naturaleza o de esencia (Caso Guzzardi contra Italia de 6 de noviembre de 1980 y caso Amuur contra Francia de 25 de junio de 1996; en lo que se refiere a la disciplina militar, caso Engel contra Holanda de 8 de junio de 1976).

Para conseguir lo anterior, el camino más adecuado, posiblemente, es el de precisar qué se entiende por "contenido 
esencial" del derecho fundamental. A ese respecto, la muy citada STC 11/1981, de 8 de abril, establece que hay dos caminos para fijar lo que se considera contenido esencial de los derechos fundamentales, que no son antitéticos sino complementarios, de forma que deben usarse ambos para determinar si se ha respetado ese núcleo en el dictado de la norma o resolución de que se trate. Esos dos caminos serán los siguientes: el primero se concretaría a partir de lo que se considera la naturaleza jurídica del derecho de que se trata, de esa forma: constituiría "el contenido esencial de un derecho subjetivo aquellas facultades o posibilidades de actuación necesarias para que el derecho sea recognoscible como pertinente al tipo descrito y sin las cuales deja de pertenecer a ese tipo y tiene que pasar a quedar comprendido en otro desnaturalizándose, por decirlo as'́”; para el segundo, se parte de los intereses jurídicamente protegidos como núcleo y médula de los derechos subjetivos, y consistiría en "hacer referencia a aquella parte del contenido del derecho que es absolutamente necesaria para que los intereses jurídicamente protegibles, que dan vida al derecho, resulten real, concreta y efectivamente protegidos".

En definitiva, y de acuerdo con constante Jurisprudencia del Tribunal Constitucional, la STC 139/2017, de 29 de noviembre, asevera que se quebranta dicho mandato, de respetar el contenido esencial del derecho, con la imposición de condiciones o requisitos de ejercicio del derecho "si lo vacían de contenido, lo someten a limitaciones que lo hacen impracticable o dificultan su ejercicio más allá de lo razonable, lo desnaturalizan o resulta irreconocible como tal derecho (SSTC 11/1981, de 8 de abril, FJ 8; 37/1987, de 26 de marzo, FJ 2; 161/1987, de 27 de octubre, FJ 5; 196/1987, de 11 de diciembre, FJ 5, y 204/2004, de 18 de noviembre, FJ 5)"; en este mismo sentido, recientemente, STC 159/2019, de 12 de diciembre. En idéntica dirección se manifiesta la doctrina, por todos PAREJO ALFONSO, quien se refiere al "reducto último que compone la sustancia del derecho, disuelto el cual ... el derecho deja de ser aquello a lo que la Constitución se refiere...todos los derechos fundamentales, por el solo hecho 
de su reconocimiento por la norma fundamental son resistentes, en su contenido esencial, frente a cualquier disposición legal o acto aplicativo que pretendiera desconocer dicho contenido" 5 .

Desde luego, si nos atenemos, y hay que hacerlo, a los términos del Real Decreto 463/2020, de 14 de marzo, por el que se declara el estado de alarma para la gestión de la situación de crisis sanitaria ocasionada por el COVID- $19^{6}$, la conclusión sólo puede ser: que se están suspendiendo derechos fundamentales (por más que en el Preámbulo del mismo se afirme que las medidas previstas: "no suponen la suspensión de ningún derecho fundamental, tal y como prevé el artículo 55 de la Constitución"). En efecto, lo que en el artículo 7 del RD se denominan: "Limitación de la libertad de circulación de las personas", con objeto, supongo, de superar la objeción de conflicto con lo dispuesto en el artículo 55.1 del texto constitucional, no es más que una suspensión del derecho fundamental a la libre circulación. Ello es así, porque en el citado precepto se prohíbe la circulación por las vías públicas, con una serie de excepciones que se exponen en un elenco cerrado; es decir: la norma es la prohibición de circulación, la excepción el permiso para muy concretas activi-

5 "El contenido esencial de los Derechos Fundamentales en la Jurisprudencia Constitucional; A propósito de la Sentencia del Tribunal Constitucional de 8 de abril de 1981", en Revista Española de Derecho Constitucional, núm. 3, septiembre/diciembre 1981, pág. 180 y s.; y más adelante: “...[S]ólo aquella parte de los elementos integrantes del contenido que sean absolutamente indispensables para la recognoscibilidad jurídica del derecho en cuanto tal, tanto en su aspecto interno (haz de facultades) como en su aspecto externo (protección de que goza), puede considerarse constitutiva del contenido esencial. Dicho de otro modo, este último es igual a las características determinantes del contenido del derecho cuya desaparición determinaría per se una transmutación de éste, que dejaría de ser lo que era para pasar a ser algo distinto. En definitiva, el contenido esencial no es otra cosa que un concepto jurídico indeterminado, con el que puede operarse, técnicamente: de ahí el carácter estrictamente jurídico predicado por la jurisprudencia constitucional de la aplicación de la garantía de dicho contenido nuclear" (pág. 187 y s.).

6 El estado de alarma declarado por el citado RD, fue prorrogado por el Real Decreto 476/2020, de 27 de marzo. 
dades $^{7}$ (que, en definitiva, se refieren a las imprescindibles para la propia supervivencia -adquisición de alimentos y fármacos, así como para acudir a centros sanitarios y entidades financieras-, ayudas a otros que lo precisen, acudir a centros de trabajo y causas de fuerza mayor o necesidad). Dicho de otra forma: se ha privado a los ciudadanos españoles del derecho a la libre circulación (y, siempre, otros que están unidos a este derecho, como el derecho de reunión o manifestación $)^{8}$.

7 En este mismo sentido PRESNO LINERA, M ("Estado de alarma por coronavirus y protección jurídica de los grupos vulnerables", en El Cronista del Estado Social y Democrático de Derecho, núm. 86-87, 2020, pág. 57), para quien: "Por cierto..., llama la atención la discordancia entre lo que prevé la Ley Orgánica 4/1981, de 1 de junio, de los estados de alarma, excepción y sitio, que parte de que el estado de alarma justifica la aprobación de restricciones y condicionamientos a una libertad general de circulación, y lo incluido en el Real Decreto 463/2020, que únicamente contempla una serie de excepciones a una limitación general de dicha libertad de circulación”.

8 'Desde luego ello no significa hacer inoperativo, ni mucho menos, el estado de alarma, pues como bien expresa la STC 83/2016, "A diferencia de los estados de excepción y de sitio, la declaración del estado de alarma no permite la suspensión de ningún derecho fundamental (art. 55.1 CE contrario sensu), aunque sí la adopción de medidas que pueden suponer limitaciones o restricciones a su ejercicio. En este sentido, se prevé, entre otras, como medidas que pueden ser adoptadas, la limitación de la circulación o permanencia de personas o vehículos en lugares determinados o condicionarlas al cumplimiento de ciertos requisitos; la práctica de requisas temporales de todo tipo de bienes y la imposición de prestaciones personales obligatorias; la intervención y la ocupación transitoria de industrias, fábricas, talleres, explotaciones o locales de cualquier clase, con excepción de domicilios privados; la limitación o el racionamiento del uso de servicios o del consumo de artículos de primera necesidad; la adopción de las órdenes necesarias para asegurar el abastecimiento de los mercados y el funcionamiento de los servicios de los centros de producción afectados por una paralización de los servicios esenciales para la comunidad cuando no se garanticen los servicios mínimos; y, en fin, la intervención de empresas o servicios, así como la movilización de su personal, con el fin de asegurar su funcionamiento, siéndole aplicable al personal movilizado la normativa vigente sobre movilización. Previsiones, todas ellas, cuya entidad adquiere particular relevancia para el enjuiciamiento que ahora abordamos".

Como puede leerse, sin acudir a la suspensión, porque lo tiene vedado, de derechos fundamentales, la declaración del estado de alarma posee un amplísimo margen de actuación. 
Pues bien, si el derecho fundamental se refiere a la libertad para deambular por el territorio nacional ${ }^{9}$, y el RD lo que ha hecho es prohibir, precisamente, esa deambulación ${ }^{10}$, hasta

9 No debe olvidarse en este punto que la libertad de circulación es condición indispensable para el libre desarrollo de la persona (Comité de Derechos Humanos. Comentarios generales aprobados por el Comité de Derechos Humanos con arreglo al párrafo 4 del artículo 40 del Pacto Internacional de Derechos Civiles y Políticos. Adición, Comentario general No. 27 (67). Libertad de circulación (artículo 12), CCPR/C/21/Rev.1/Add.9**, 1 de noviembre de 1999)

10 Unida a la cual va añadido el control de las vías de comunicación y una fuerte disminución de la disponibilidad de transporte público (véase en este sentido, la Orden INT/262/2020, de 20 de marzo, por la que se desarrolla el Real Decreto 463/2020, de 14 de marzo, por el que se declara el estado de alarma para la gestión de la situación de crisis sanitaria ocasionada por el COVID-19, en materia de tráfico y circulación de vehículos a motor, modificada por la Orden INT/284/2020, de 25 de marzo). Estas últimas medidas, en solitario, sí se podrían categorizar como de restricción o limitación de la libre circulación, en tanto y en cuanto se deja intacto el núcleo del derecho (la libertad de circulación) pero se imponen restricciones en su ejercicio. Nada que ver estas medidas con unas en las que se confinan en sus residencias habituales a los ciudadanos; ante un confinamiento no cabe hablar de restricción a la libertad de circulación, sino una suspensión del derecho.

En este punto no es inadecuado recordar que la LO 4/1981, en su artículo once habilita al Gobierno a adoptar algunas medidas que deben ser tomadas, precisamente, en un Real Decreto: "Con independencia de lo dispuesto en el artículo anterior, el decreto de declaración del estado de alarma, o los sucesivos que durante su vigencia se dicten, podrán acordar las medidas siguientes..."; y que sean tomadas esas medidas por Real Decreto es lógico, ya que de acuerdo con el artículo ocho.Dos de la LO 4/1981: "El Gobierno también dará cuenta al Congreso de los Diputados de los decretos que dicte durante la vigencia del estado de alarma en relación con éste". Todo ello goza de una lógica aplastante en términos democráticos, pues ya que se están limitando derechos fundamentales (que no son disponibles, con carácter general, por el Gobierno), en momentos, además, de emergencia, lo único razonable es que esos Reales Decretos (que son materialmente de necesidad) sean controlados en su contenido -con las limitaciones implícitas en ese "dar cuenta"- por el Congreso.

Debe anotarse, además, que el artículo doce.Uno de la LO 4/1981, dispone: "En los supuestos previstos en los apartados a) y b) del artículo cuarto, la Autoridad competente podrá adoptar por sí, según los casos, además de las medidas previstas en los artículos anteriores, las establecidas en las normas para la lucha contra las enfermedades infecciosas, la protección 
el punto de que se conmina a los ciudadanos a permanecer en sus domicilios bajo amenaza de sanciones (penales y administrativas), lo que se ha efectuado es: vaciar de contenido el derecho, convirtiéndolo en irreconocible, desnaturalizándolo. El afirmar a continuación que nos hallamos ante una situación de limitación o restricción del derecho, no constituye más que una

del medio ambiente, en materia de aguas y sobre incendios forestales"; precepto éste que se encuentra en conexión con el séptimo de la misma Ley, que preceptúa: "A los efectos del estado de alarma la Autoridad competente será el Gobierno o, por delegación de éste, el Presidente de la Comunidad Autónoma cuando la declaración afecte exclusivamente a todo o parte del territorio de una Comunidad".

Pues bien, a pesar de lo anterior, el artículo 4.3 del RD 463/2020, por el que se declara el estado de alarma, preceptúa: "Los Ministros designados como autoridades competentes delegadas en este real decreto quedan habilitados para dictar las órdenes, resoluciones, disposiciones e instrucciones interpretativas que, en la esfera especifica de su actuación, sean necesarios para garantizar la prestación de todos los servicios, ordinarios o extraordinarios, en orden a la protección de personas, bienes y lugares, mediante la adopción de cualquiera de las medidas previstas en el artículo once de la Ley Orgánica 4/1981, de 1 de junio". De esta manera son los ministros, a través de órdenes ministeriales, resoluciones, disposiciones e instrucciones interpretativas, quienes, en virtud de una autoridad delegada, están limitando o restringiendo derechos fundamentales.

Pues bien, esa delegación de competencias estimo que es de dudosa legalidad; y ello es así no por las prohibiciones al respecto de la Ley 40/2015, puesto que al Real Decreto que se dicta declarando el estado de alarma se le reconoce por el Tribunal Constitucional valor de Ley (lo que no deja de ser muy llamativo), y por tanto derogaría los preceptos de la Ley 40/2015 que entraran en contradicción con el Real Decreto y durante el tiempo de vigencia de éste (STC 83/2016, de 28 de abril: "Así pues, aunque formalizada mediante decreto del Consejo de Ministros, la decisión de declarar el estado de alarma, dado su contenido normativo y efectos jurídicos, debe entenderse que queda configurada en nuestro ordenamiento como una decisión o disposición con rango o valor de ley. Y, en consecuencia, queda revestida de un valor normativo equiparable, por su contenido y efectos, al de las leyes y normas asimilables cuya aplicación puede excepcionar, suspender o modificar durante el estado de alarma"), sino por el tenor de los preceptos señalados de la propia LO 4/1981, que especifica quién es "autoridad competente" "a los efectos del estado de alarma"; y obviamente el RD declarativo del estado de alarma no puede modificar ni derogar la LO de regulación, precisamente, de los estados de alarma, excepción y sitio. 
grosera manipulación del texto constitucional. En este sentido es verdaderamente burdo el tratar de convencer a un ciudadano, al que se le ha prohibido durante semanas salir de su domicilio habitual, que no se le ha suspendido el derecho a la libre circulación, sino que meramente se le ha limitado o restringido su ejercicio...cuando lo único que se le permite es transitar desde la cocina de su vivienda al dormitorio. Pues bien, si confinar en la vivienda es limitación a la libre circulación por el territorio nacional ¿qué contenido tendrá la suspensión del derecho?

6. ¿Cabría, entonces, ante una pandemia como la que sufrimos, la posibilidad de decretar, en lugar del "estado de alarma", el "estado de excepción"? Pues bien, de acuerdo con el artículo 13 de la Ley Orgánica 4/1981, de 1 de junio, de los estados de alarma, excepción y sitio:

"Uno. Cuando el libre ejercicio de los derechos y libertades de los ciudadanos, el normal funcionamiento de las instituciones democráticas, el de los servicios públicos esenciales para la comunidad, o cualquier otro aspecto del orden público, resulten tan gravemente alterados que el ejercicio de las potestades ordinarias fuera insuficiente para restablecerlo y mantenerlo, el Gobierno, de acuerdo con el apartado tres del artículo ciento dieciséis de la Constitución, podrá solicitar del Congreso de los Diputados autorización para declarar el estado de excepción".

De la comparación de este precepto con el incluso en el artículo cuarto de la LO 4/1981, pareciera que el estado de alarma está vinculado a "alteraciones de la normalidad" referidas, por una parte, a la presencia de grandes siniestros de carácter "natural" [artículo cuarto, apartados a): Catástrofes, calamidades o desgracias públicas, tales como terremotos, inundaciones, incendios urbanos y forestales o accidentes de gran magnitud, y b) las ya referidas crisis sanitarias, tales como epidemias y situaciones de contaminación graves], y por otra, a situaciones que ya no poseen ese carácter "natural", sino más bien una naturaleza 
ambigua: casos de paralización de servicios públicos esenciales para la comunidad [apartado c)] o situaciones de desabastecimiento de productos de primera necesidad [apartado d)]. Estos dos últimos supuestos, qué duda cabe, pueden deberse a situaciones vinculadas con el orden público, con alteraciones del orden público; afirmación esta última que echa por tierra esa artificial división que algunos han querido ver entre la declaración de los estados de alarma (como situaciones con origen natural o humano no vinculadas a alteraciones de orden público ${ }^{11}$ ) y excepción (gravísimas alteraciones del orden público). En realidad, y como dijera CRUZ VILLALÓN, el estado de alarma es un totum revolutum, en el que se confunden catástrofes y huelgas ${ }^{12}$.

Sin embargo, el estado de excepción pareciera vinculado con situaciones excepcionales de alteración del orden público, pero de un "orden público", como concepto, alejado de concepciones añejas, que algunos siguen manteniendo, como equiparable a la mera paz y quietud. En efecto, ya hace algunos años advertía ${ }^{13}$ que el orden público, desde el punto de vista constitucional, exige ser comprendido no en un sentido de "quietud" de los ciudadanos sino en el de participación activa de estos en la totalidad del Ordenamiento ${ }^{14}$; ello requiere desterrar como

11 Véase, SANDOVAL, JA "Presupuestos del estado de alarma y repercusiones penales a propósito de la crisis de los controladores civiles de tránsito aéreo", en Revista Electrónica de Ciencia Penal y Criminología, 14-11, 2012, pág. 11:11.

12 "La protección extraordinaria del Estado", en E. GARCÍA DE ENTERRÍA y otros (coordinador) La Constitución española de 1978. Estudio sistemático, Madrid, 1981, pág. 694.

13 ÁLVAREZ GARCÍA, FJ "La nueva reforma penal de 2013", en Eunomia, núm. 6, marzo-agosto, 2014, págs. 29 y ss.

14 Prescindo, pues, de aquellas concepciones que, abriendo el concepto a la moral, ética, costumbres sociales, sentimiento social, etc., nos arrojan a la más absoluta inseguridad y a una manipulación por necesidad contingente. Por ello coincido con quien fuera mi Profesor de Derecho Administrativo CARRO FERNÁNDEZ-VALMAYOR ("Sobre los conceptos de orden público, seguridad ciudadana y seguridad pública", en Revista Vasca de Administración Pública, núm. 27, 1990, pág. 15), cuando afirma: “el orden público sólo puede ser un orden positivo, esto es, un orden establecido por 
referente conceptos como el de "mantenimiento de la tranquilidad ciudadana" 15 , u otros similares como contenido material del orden público, y sustituirlos por otros que se refieran a la participación activa plena de los ciudadanos en la vida jurídica (con expresión de todos sus derechos, lo que implica la construcción positiva del concepto $\left.{ }^{16}\right)$.

En este sentido, y no sólo ni principalmente por argumentos de intervención mínima, la intrusión pública en la vida ciudadana, decía, ha de retrasarse hasta aquellas situaciones en que las condiciones mínimas de ejercicio de esa participación de los ciudadanos en la vida jurídica se vean seriamente comprometidas. Dicho de otra forma: el ejercicio público de derechos constitucionales como los de libre circulación, reunión, manifestación, expresión, etc., no puede verse como un supuesto de compromiso para el orden público, sino como plena realización de éste ${ }^{17}$, formando parte del contenido de su concepto ${ }^{18}$. A esto

el Derecho y no por una difusa conciencia social que no tenga traducción en concretas normas jurídicas. Así, sólo será constatable una perturbación del orden público si efectivamente ha existido violación de derechos, bienes jurídicos o libertades de los particulares o si se ha visto afectado el ejercicio de las competencias públicas reguladas por el Ordenamiento jurídico".

15 Mero "orden en la calle", esa trivialización del concepto al que se refería L. MARTÍN RETORTILLO ((1975), La cláusula de orden público como límite -impreciso y creciente-del ejercicio de los derechos, Madrid, 1975, pág. 42.

16 Véase en este sentido la ya vetusta STC 19/1985, de 13 de febrero, según la cual "el respeto a los derechos fundamentales y libertades públicas garantizados por la Constitución es un componente esencial del orden público". Es decir, "perturbación" del orden público no es un equivalente a alteración de las condiciones en las que habitualmente se desenvuelve la vida ciudadana, entendimiento este que se corresponde más -y que entronca con algunos "tradicionales"- con la exclusión material de los ciudadanos de la vida pública y su enclaustramiento en un protagonismo meramente electoral.

17 Obviamente, no sólo el ejercicio de derechos constitucionales puede comprometer el orden público, y ello es así porque éste es un foco de atracción o soporte de cualesquiera manifestaciones de la vida individual o colectiva; lo que sucede es que el ejercicio de derechos y libertades públicas constitucionalmente reconocidos (comenzando, naturalmente, por su mismo desarrollo) será normalmente el que rellene de contenido material el concepto de 
debe dársele una doble trascendencia: por una parte ha de entenderse como modo no sólo legítimo sino necesario de expresión ciudadana para la adecuada conformación del orden político; así, las protestas, reuniones o manifestaciones públicas han de ser conceptuadas no como elementos de sospecha de alteración del orden, sino como expresión de participación ciudadana en la realización del orden constitucional, cuyo desarrollo, por lo tanto, no sólo no debe ser obstaculizado o reprimido sino alentado $^{19}$. En segundo término, y dada la importancia de los bienes

orden público (y, en realidad, lo será el substrato de todos ellos: la dignidad y el libre desarrollo de la personalidad).

18 Desde luego no es esta la idea que está presente en el artículo 1 de la LO 4/2015, de 30 de marzo, de protección de la seguridad ciudadana, según el cual: "La seguridad ciudadana es un requisito indispensable para el pleno ejercicio de los derechos fundamentales y las libertades públicas, y su salvaguarda, como bien jurídico de carácter colectivo, es función del Estado, con sujeción a la Constitución y a las Leyes. 2. Esta Ley tiene por objeto la regulación de un conjunto plural y diversificado de actuaciones de distinta naturaleza orientadas a la tutela de la seguridad ciudadana, mediante la protección de personas y bienes y el mantenimiento de la tranquilidad de los ciudadanos". Como puede comprobarse, la "seguridad ciudadana" (concepto más restringido que el de "orden público" pero que participa de éste en sus elementos esenciales; PAREJO ALFONSO entiende -Seguridad pública y policía administrativa de seguridad. Problemas de siempre y de ahora para el deslinde, la decantación y la eficacia de una responsabilidad nuclear del Estado administrativo, Valencia, 2008, pág. 75- que "La seguridad pública supone en todo caso una noción más precisa que la de orden público") constituye un momento previo y externo al ejercicio de los derechos constitucionales.

Hay que señalar que no pocos autores manifiestan no haber entendido suficientemente el problema; es el caso de E. BLAY ("El control policial de las protestas en España", InDret, núm. 4, pág. 8) cuando afirma en un pasaje de su obra -en la que importa toda una serie de modelos clasificatorios de dudosa utilidad-: "Bajo el modelo de gestión negociada, se considera necesario que policía y manifestantes negocien previamente para poder garantizar los derechos de expresión y reunión y asegurar niveles tolerables de alteración de la convivencia". Digo que hay insuficiente comprensión del problema porque una manifestación no supone per se, nunca, alteración alguna de la convivencia, sino, precisamente, realización de la misma.

19 Sólo los regímenes totalitarios pueden pretender el acallamiento ciudadano, y sólo éstos pueden ver como un peligro, como "una molestia democrática", la realización de manifestaciones o reuniones. Por el contrario, la plena 
en conflicto, no deben construirse los tipos sancionadores partiendo del presupuesto de que son los derechos de manifestación o reunión los que deban ceder -incluso anticipadamente- ante cualquier alteración en la posibilidad de realización de otros derechos ${ }^{20}$, sino justamente a la inversa -tal y como se lleva a cabo en otras situaciones de ponderación-, amoldar esos otros derechos a la situación de conflicto ${ }^{21}$. Es decir, el concepto de orden público como substrato y condicionante para el ejercicio de otros derechos, ha de construirse de modo integrado con el ejercicio de los derechos constitucionales ${ }^{22}$.

Pues bien, esta idea, alejada de un concepto de orden público como mera "tranquilidad en la calle", está más presente en un texto de hace cuarenta años que en la reciente Ley de Seguridad Ciudadana. En efecto, el artículo trece.uno de la LO 4/1981, dice:

\section{"Cuando el libre ejercicio de los derechos y liber- tades de los ciudadanos, el normal funcionamiento de las instituciones democráticas, el de los servicios públicos esenciales para la comunidad, o cualquier otro aspecto del orden público resulten tan grave- mente alterados que el ejercicio de las potestades or- dinarias fuera insuficiente para restablecerlo y man- tenerlo, el Gobierno, de acuerdo con el apartado tres}

realización democrática exige esa confrontación, esa crítica que se produce, también, a través de manifestaciones y reuniones.

20 Llamo la atención nuevamente sobre la no utilización por mi parte de términos como "alteración de la vida ciudadana u otros parecidos", y ello porque parto de la idea de que las manifestaciones o reuniones públicas forman parte de esa vida ciudadana, y por ello no deben entenderse como alteración de la misma.

21 Para la diferenciación entre intervención penal y administrativa en este ámbito, véase PAREJO ALFONSO, L Seguridad pública y policía administrativa de seguridad..., ob. cit., págs. 52 y ss.

22 Sobre su evolución histórica, véase MARTÍN RETORTILLO, L "El orden público como límite al derecho de libertad religiosa", en id., Bajo el signo de la Constitución, Instituto de Estudios de Administración local, Madrid, 1983, passim. 
del artículo ciento dieciséis de la Constitución, podrá solicitar del Congreso de los Diputados autorización para declarar el estado de excepción".

Es decir, el ejercicio de los derechos y libertades, tal y como preconizaba más atrás, forma parte de la concreción del concepto mismo de orden público; éste no es presupuesto de ese ejercicio, sino que resulta integrado por la puesta en acción de derechos y libertades ${ }^{23}$. Así pues, cuando el ejercicio de los derechos y libertades resulten gravemente alterados (por ejemplo, el derecho a la vida en las actuales circunstancias por efecto de la pandemia), el Gobierno puede solicitar al Congreso la declaración del estado de excepción.

No se trata, pues, de identificar el substrato para la declaración del estado de excepción con gravísimos desórdenes públicos (en el sentido de los delitos recogidos en los artículos 557 y ss. del Código Penal), sino, más sencillamente, que por las circunstancias de que se trate, ese "libre ejercicio de los derechos y libertades de los ciudadanos" resulte muy gravemente alterado.

En las actuales circunstancias, cuando el avance y características de la enfermedad se ha convertido en pandemia, y el ejemplo de lo sucedido en otras naciones pone de manifiesto que el derecho a la vida (artículo $15 \mathrm{CE}$ ), a la salud (artículo 15 $\mathrm{CE}^{24}$ ), al libre desarrollo de la personalidad (artículo $10 \mathrm{CE}$ )..., resultan gravísimamente alterados, y se tiene conciencia de que las facultades ordinarias a ejercer por el Estado no resultan suficientes para detener lo que, de otra forma, puede convertirse en una terrible mortandad, equiparable a otras históricas...hay que suspender derechos fundamentales (de acuerdo con lo dictami-

23 Esta definición fue, con razón, alabada en su momento por no pocos autores, valga por todos SERRANO ALBERCA, "Artículo 116.2 CE", en F. GARRIDO FALLA, Comentarios a la Constitución, Madrid, págs. 1582 y s.

24 Resulta llamativo que ya en el año 1978 los redactores de la Constitución se refirieran, todavía, a la "integridad" y no a la "salud", y ello por más que la salud (ya no integrada en el Capítulo III entre los principios rectores de la política social y económica) se ha querido entender como incorporada en esa "integridad" a la que se refiere el precepto constitucional. 
nado por los especialistas); y para ello, no hay base, como se ha visto más atrás, con la declaración del estado de alarma, hay que acudir al estado de excepción. Sólo de esta forma se puede confinar a los ciudadanos en su casa hasta límites casi insoportables, suspender el ejercicio de los derechos de circulación, de reunión y limitar fuertemente el mismo derecho a la libertad ${ }^{25}$.

Pero la situación provocada por la pandemia no sólo ha afectado al ejercicio de derechos y libertades, pues resulta evidente, y no es preciso argumentar más, que un servicio público esencial (el "más esencial" en una situación de pandemia), ya muy deficiente desde hace años ${ }^{26}$, ha resultado absolutamente sobrepasado en esta situación. La realidad en los servicios sanitarios es tan de emergencia como es por todos conocido, que sólo la disminución de la afluencia de ciudadanos a los mismos haría posible que estos pudieran funcionar ya no con normalidad, sino, simplemente, que pudieran satisfacer de alguna manera las demandas de atención a los ciudadanos. Es decir: la gravísima alteración del funcionamiento de la sanidad pública ${ }^{27}$, que es algo más que un servicio público esencial ${ }^{28}$, ya constituye

25 No cabe duda de que, además, resultan, y resultarán afectados otros derechos. En este sentido la parte más crítica de la sociedad española -y seguramente la más responsable- teme por integrantes fundamentales de la democracia; en este último sentido, intranquiliza extraordinariamente el dictado de la Orden SND/297/2020, de 27 de marzo, por la que se encomienda a la Secretaría de Estado de Digitalización e Inteligencia Artificial, del Ministerio de Asuntos Económicos y Transformación Digital, el desarrollo de diversas actuaciones para la gestión de la crisis sanitaria ocasionada por el COVID-19, por lo que puede suponer de invasión de la privacidad.

26 "Measuring performance on the Healthcare Access and Quality Index for 195 countries and territories and selected subnational locations: a systematic analysis from the Global Burden of Disease Study 2016", The Lancet, vol. 391, junio 2018 (https://www.thelancet.com/action/showPdf?pii $=\mathrm{S} 0140-6736 \% 2818 \% 2930994-2)$.

27 La privada, tan premiada durante los últimos veinticinco años a base de "desmontar" la sanidad pública, no ha asumido -con carácter general- las responsabilidades de las que se debería haber hecho cargo.

28 Desde luego no cabe duda que la sanidad es un servicio público esencial, lo que goza de reconocimiento expreso tanto por la Jurisprudencia (SSTS, Sala de lo Contencioso, 148/2017, de 1 de febrero; 9 de julio de 2012, núm. de 
suficiente base para la declaración del estado de excepción de acuerdo a lo previsto en el artículo trece.uno de la LO 4/198129.

Todo, como se ve, lleva hacia la declaración del estado de excepción y el respeto a la norma constitucional como camino más idóneo para afrontar esta gravísima crisis, tal y como han señalado ALEGRE ÁVILA y SÁNCHEZ LAMELAS ${ }^{30}$.

recurso 4202/2011, y 16 de diciembre de 2010 -núm. de recurso 1877/2009), como por la legislación [artículo 2 a) de la Ley 8/2011, de 28 de abril, por la que se establecen medidas para la protección de las infraestructuras críticas: "Servicio esencial: el servicio necesario para el mantenimiento de las funciones sociales básicas, la salud, la seguridad, el bienestar social y económico de los ciudadanos, o el eficaz funcionamiento de las Instituciones del Estado y las Administraciones Públicas"; es de destacar, asimismo, que el RD 463/2020, de 14 de marzo, por el que se declaró el estado de alarma, reenvía, en su artículo 17, para la determinación de servicios esenciales, a lo previsto en la Ley 8/2011).

En cualquier caso, y más allá de lo anterior, la sanidad, sin duda alguna, se constituye, también, en uno de los pilares básicos del Estado social, del Estado del bienestar (artículo $43 \mathrm{CE}$ ).

29 En realidad, da la impresión de que la resistencia de los poderes públicos a la declaración del estado de excepción en lugar del de alarma durante la emergencia provocada por el "corona virus", está más vinculada, no a las viejas concepciones del orden público a las que he hecho referencia más arriba, sino al recuerdo de los estados de excepción declarados durante la Dictadura.

30 "[L]a muy limitada duración temporal de la declaración del estado de alarma [quince días, bien que prorrogables con autorización del Congreso de los Diputados ex artículo 6.2 LOEAES] como, en especial, la inviabilidad de que a su amparo pueda suspenderse el ejercicio de derechos fundamentales [en particular, de los reconocidos, como se viene diciendo, en los artículos 17 y 19 del texto constitucional], torna en insuficiente el marco normativo del estado de alarma y, con él, de las medidas cuya adopción puede habilitarse, para hacer frente a una situación del tal gravedad como la generada por Emergencia vírica", ob. cit. 